\title{
Poetic Language and the Computer: A Corpus Stylistic Study of The Waste Land
}

\author{
Eman Adil Jaafar \\ Department of English \\ College of Education for Women \\ University of Baghdad \\ eman_jafer@coeduw.uobaghdad.edu.iq
}

DOI: https://doi.org/10.36892/ijlls.v3i1.525

$\begin{array}{ll}\begin{array}{l}\text { Received: } \\ \text { 25/02/2021 }\end{array} & \text { This study aims at analyzing one of the significant poems of the twentieth } \\ \text { Accepted: } & \text { century, The Waste Land by T.S. Eliot. By means of applying the tools of the } \\ \text { 10/03/2021 } & \text { computer, namely; Wmatrix (Rayson 2009) and WebCorp Live (Birmingham } \\ & \text { City University). This paper seeks 1. To examine whether corpus stylistics can } \\ \text { Ke helpful in analyzing a single poem 2. To verify the importance of corpus } \\ \text { Corpus } & \text { tools in interpreting poetic language. Moreover, this study attempts to } \\ \text { poetry, Stylistics, } & \text { examine key semantic domains, keywords, and concordances in the poem. This } \\ \text { live, Wmatrix } & \text { study proves that corpus tools are crucial in matters of saving time, reaching } \\ & \text { to accurate results and achieving much more objectivity than applying only } \\ & \text { the qualitative method in analyzing the data. Thus, it is recommended to } \\ & \text { integrate both methodologies (qualitative and quantitative) in the study of } \\ \text { poetic language. } & \end{array}$

\section{INTRODUCTION}

This paper presents a corpus-stylistic analysis of T.S.Eliot's poem The Waste Land, henceforth (TWL). The poem will be analyzed according to the corpus stylistic approach. Baker, Hardie, and McEnery (2006, p.48-49) define the word corpus (plural "corpora") is a Latin word that refers to a combination of written and spoken texts. The word corpus also has the meaning of "body". The texts are generally stored and analyzed electronically. Corpus stylistic starting to appear in the discipline of linguistics has become increasingly popular in recent years. It is a combined process to the study of the language of literature (for more details about corpus stylistics see Ho, 2011; Mahlberg, 2014).

Hunston (2002, p. 2-3) pinpoints that "Although a corpus does not contain new information about language by using software packages which process data, we can obtain a new perspective on the familiar". To put it differently, corpora reflect the real authentic language and by using quantitative as well as qualitative methodology in terms of integrating manual and corpus analysis one can get interesting facts about patterns of language.

Bujanova (2013) sees corpus stylistics as "a way of bringing the study of language and literature close together"(p.3). Furthermore, Mahlberg (2014) maintains that corpus stylistics joins principles from corpus linguistics and literary stylistics. Though, subsequent a corpus stylistic process be able to help to mark the uses of the new linguistic of the language of texts by 
quantitative methods (p.378-380). Moreover, Wynne (2005) pointed out some underlying similarities of approach: "Traditional and computational forms of stylistics have more in common than is obvious at first sight. Both rely on the close analysis of texts, and both benefit from opportunities for comparison" (p.677-679).

Mahlberg \& McIntyre (2011, p.205) ascertain that corpus stylistics does not substitute the qualitative analyses, but rather foster the computational analyses. Furthermore, they argued rightly, that "corpus methods can aid the identification of elements of a text worthy of further qualitative analysis" (p.223). In this regard, computer programs can aid researchers immensely as Rayson (2003, p.4) pinpoints that "Although the computer saves us time with its processing of the texts into frequency lists, it presents us with so much information that we need a filtering mechanism to pick out significant items before the analysis can proceed".

\section{METHODOLOGY}

The following methodological steps are followed to conduct this study:

1-Preparing the corpus of the selected text and converting it into a plain text form (txt).

2-Using WebCorp Live as the tool to examine Keywords by focusing on content words. This tool enables researchers from isolating function words like (articles, prepositions, pronouns

...etc) in orderto give the needed attention to the words that carry meaning.

3-Using Wmatrix software to benefit from its unique advantage of identifying key semantic domains.

\section{RELATED WORK ON CORPUS STYLISTICS AND POETRY}

Brooke, Hammond, \& Hirst (2015) conducted research seeking distinguished voices in The Waste Land. Their major aim is to find out whether the computer can locate different voices as in human analysis (p.4). Similar to the current study, Jaafar (2019) analyzed Seamus Heaney's poem "A Herbal" by means of computational tools. It is concluded that the integration of both quantitative and qualitative approaches can be fruitful in terms of obtained objective results. In contrast, Jaafar (2014) conducted a manual qualitative study to analyse selected poems that focuses on deviation and other stylistic tools.

\section{TYPES OF CORPUS TOOLS}

In fact, there are a variety of corpus tools or software programs that can be useful in conducting corpus stylistic research. Researchers should have an idea about such tools and then they can select the suitable one for their analysis. Some of these toolkits, for example, WordSmith tools which is a word list tool, a concordance tool, and a keyword list tool. Another web-based corpus software Wmatrix ( Rayson 2009) which is distinguished from other tools by its unique feature of identifying key semantic domains as well as having the function to automatic POS tagging. AntConc (Anthony 2004) is free software that can be used freely by anyone who has an interest in finding n-grams, keywords, concordances, and collocations. Moreover, Mahlberg \& Smith's (2012) tool CLiC (Corpus Linguistics in Cheshire). One more beneficial tool is WebCorp Live is a search engine for linguists, teachers, and learners that is useful to retrieve corpus data online. 


\section{THE DATA}

The Wasteland is considered T.S.Eliot's masterpiece written in 1922. It is one of the complicated poems of the twentieth century. It depicts the destructed life after the First World War. Not one this, but also it shows the decline of moral values of the society after the war. It is an obscure poem due to the inclusion of many allusions and references from other texts. It was written he underwent personal difficulties in his first marriage. Its complexity made it one of the crucial and significant works of the English literature and in particular of the modern age, which contain some lines from a variety of languages such as German, French, Spanish and Hindi. ( see,North , 2001; McHale \& Stevenson 2006).

The Waste Land is a long poem consists of a total 3,028 words and divided into five sections. The main ideas and themes of the poem include; death, corruption and many other pessimistic views of the life postwar. It is considered the mouthpiece of that time. However, the last line of the poems shows a different shift. The Sanskrit word 'Shanith' means peace' is repeated three times.

The first section "The Burial of the Dead" contains four different characters each one has a story that is not completed. The language of the poem contains some verses written in both German and French which add difficulty in understanding and interpreting the text.

Section two "A Game of Chess" narrates stories of women of different social classes the high and the lower class. These women have their own dilemma. This section consists of 261 words. Section Three The Fire Sermon is the longest section of the poem. Section four Death by Water. This the shortest section of the poem. Section five "What the Thunder Said" is pessimistic and shows a harsh reality in terms of the imagery of destruction, there is a temporal renewal but again the destruction is near and final.

\section{The Analysis}

Roughly speaking, under the umbrella of qualitative analysis, the poem depicts boredom and monotony of the modern life, which illustrated by means of continuous repetitions of words, phrases, and sentences throughout the text, examples include:

"My nerves are bad tonight. Yes, bad. Stay with me."Speak to me. Why do you never speak.

Speak.

"What are you thinking of? What thinking?

What?"I never know what you are thinking.

Think."

I think we are in rats' alley

Where the dead men lost their bones.

"What is that noise?"

The wind under the door. 
"What is that noise now? What is the wind doing?"

Nothing again nothing.

"Do

"You know nothing? Do you see nothing? Do you remember

"Nothing?" ( Section II A Game of Chess)

https://www.poetryfoundation.org/poems/47311/the-waste-land

These lines give a clear idea about the nothingness and the hollowness of the people of the modern life.

In addition to that, T.S. Eliot uses allusions and includes many images and references to famous works and personalities in the text. He creates ideas and leaves them unfinished which in turns gives the complexity of the poem. Another important aspect of the poem is the inclusion of many voices or characters by using personal pronouns like ( she, he, I, you). This can also be the reason behind the difficulty of the poem.

The poem consists of a total 3,028 words. According to WebCorp Live calculation, the number of content words is 1034 and the total number with repetitions throughout the text is 1552 .

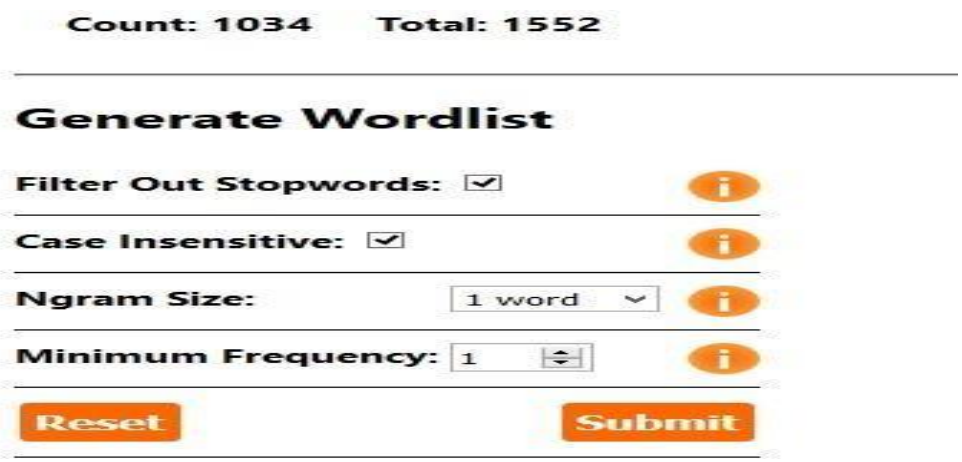

\section{Screenshot (1) Wordlist in The Wasteland}

Screenshot (1) illustrates that by copying and pasting the text in the specific area the generator of the wordlist count the words according to the choices made by the researcher, for example, the ngram size ( single words) and the option filter out stop words or high-frequency words( skipping function words from the retrieval results).

In the first section of the text The Burial of the Dead, contains (252) words repeated once one and excluding high-frequency words like (articles and pronouns and other function words). The most repeated word is 'Dead' which is mentioned five times only in this part.

10 occurrences.
MIGLIOR FABBRO I. The Burial of the Dead April is the cruellest month, breed 1
month, breeding Lilacs out of the dead land, mixing Memory and desire, st 2
ges, where the sun beats, And the dead tree gives no shelter, the cricket 3
$s$ failed, I was neither Living nor dead, and I knew nothing, Looking into 4
Mary Woolnoth kept the hours with a dead sound on the final stroke of nine.
hink we are in rats alley Where the dead men lost their bones. What is that 5
And walked among the lowest of the dead, , Bestows one final patronising ki 7
hlebas the Phoenician, a fortnight dead, Forgot the cry of gulls, and the 8
mountains He who was living is now dead We who were living are now dying Wit 9
re were only water amongst the rock Dead mountain mouth of carious teeth that 10


Screenshot (2) the Retrieval Results of the Word 'Dead'

The word 'dead' for example, occurs (10) times throughout the text. Here are some examples:

1. Dead April.

2. Dead land.

3. Dead tree.

4. Dead sound.

5. Dead mountain.

These words mentioned with the word 'dead' to give them a kind of pessimistic personification, related to the pessimistic atmosphere of the poem.

In addition to that, part one contains some verses written in both German and French.

\subsection{Keywords Analysis}

Wmatrix is employed to identify the main keywords in the $T W L$. The selected reference corpora is BNC which contain 100 million words, $90 \%$ percent consists of written data the rest $10 \%$ percent of spoken data. Here, is this paper The BNC sampler (1 million words) consists of many categories. The BNC Written Imaginative sampler is used as a reference corpus. This sampler contains literary works and creative writing. It is necessary to use a reference corpus that suits the content of the text to be analyzed and examined (cf Culpeper, 2009, McIntyre 2010).

\begin{tabular}{|c|c|c|c|c|c|c|c|c|c|}
\hline & & Item & $\mathrm{O} 1$ & +1 & O2 & 62 & & LL & GDIYF \\
\hline 1 & Conosrdance & $c$ & 12 & 0.98 & 20 & 0.00 & + & 66.94 & 3329.58 \\
\hline 2 & Conosrdance & rock & 22 & 0.98 & 13 & 0.02 & + & 62.98 & 6384.29 \\
\hline 3 & Conosrdance & mountaing & 8 & 0.28 & 4 & 0.00 & + & $\$ 4.46$ & 15226.52 \\
\hline 4 & Conosrdance & Jug & s & 0.28 & 5 & 0.00 & + & $\$ 2.44$ & 12161.21 \\
\hline 5 & Conosrdance & water & 15 & 0.52 & 73 & 0.03 & + & $\$ 2.09$ & 1474.64 \\
\hline 6 & Conosrdance & kurry_up & 5 & 0.17 & 0 & 0.00 & + & 43.52 & $172: 7628818479 \$ 136.00$ \\
\hline 7 & Conosrdance & goonight & 5 & 0.17 & 0 & 0.00 & + & 43.52 & $172: 7628818479 \$ 136.00$ \\
\hline 8 & Conosrdance & violet & 4 & 0.24 & 0 & 0.00 & + & 24.82 & 137741035701796864.00 \\
\hline 9 & Conosrdance & ne & 4 & 0.24 & 0 & 0.00 & + & $\$ 4.82$ & 137741035702796864.00 \\
\hline 10 & Conosrdance & co & 4 & 0.24 & 0 & 0.00 & + & 34.82 & 137741035701796864.00 \\
\hline 21 & Conosrdance & cane & 4 & 0.24 & 0 & 0.00 & + & $\$ 4.82$ & 137742035702796864.00 \\
\hline 12 & Conosrdance & Albere & 4 & 0.24 & 2 & 0.00 & + & 29.84 & 30553.03 \\
\hline 23 & Conosrdance & burning & 5 & 0.17 & 3 & 0.00 & + & 26.40 & 4689.54 \\
\hline 24 & Conosrdance & under & 10 & 0.34 & 30 & 0.04 & + & 26.32 & 857.91 \\
\hline 15 & Conosrdance & kones & 5 & 0.17 & $\ni$ & 0.00 & + & 25.50 & 4157.37 \\
\hline 16 & Conosrdance & 1a & 4 & 0.14 & 3 & 0.00 & + & 25.33 & $101: 7.68$ \\
\hline 17 & Conosrdance & departed & 4 & 0.14 & 3 & 0.00 & + & 25.33 & $101: 7.68$ \\
\hline 18 & Conosrdance & kas & 12 & 0.98 & 2823 & 1.27 & - & 24.85 & -70.14 \\
\hline 19 & Conosrdance & crop & 5 & 0.17 & 21 & 0.00 & + & 23.93 & 3383.30 \\
\hline 20 & Conosrdance & shadow & 4 & 0.24 & 4 & 0.00 & + & 23.83 & 7563.26 \\
\hline 22 & Conosrdance & cead & 20 & 0.94 & 205 & 0.05 & + & 22.81 & 629.83 \\
\hline 22 & Conosrdance & unreal & 3 & 0.10 & 1 & 0.00 & + & 22.64 & 22889.77 \\
\hline 23 & Conosrdance & shantih & 3 & 0.10 & 1 & 0.00 & + & 22.64 & 22889.77 \\
\hline 24 & Conosrdance & fal11ng_down & 3 & C. 10 & 1 & 0.0 & $0+$ & 21.6 & $64 \quad 22889.77$ \\
\hline 25 & Conosrdance & I1resias & 3 & 0.10 & 1 & 0.00 & + & 21.64 & 22889.77 \\
\hline 26 & Conosrdance & thunder & 4 & 0.14 & 5 & 0.00 & + & 21.51 & 3008.84 \\
\hline 27 & Conosrdance & dry & 6 & 0.21 & 31 & 0.01 & + & 20.23 & 1383.21 \\
\hline 28 & Conosrdance & $1 t$ & 15 & 0.52 & 3031 & 1.36 & - & 19.82 & -62.08 \\
\hline 29 & Conosrdance & to & 32 & $\therefore .67$ & 4802 & 2.16 & - & 19.48 & -50.53 \\
\hline 30 & Conosrdance & towers & 3 & 0.10 & 2 & 0.00 & + & 19.43 & 11394.89 \\
\hline 32 & Conosraance & epring & 4 & 0.24 & 9 & 0.00 & + & 19.00 & 3305.89 \\
\hline 32 & Conosrdance & welalala & 2 & 0.67 & 0 & 0.00 & + & 27.42 & 63870517850898132.60 \\
\hline
\end{tabular}




\begin{tabular}{|c|c|c|c|c|c|c|c|}
\hline 33 & Concordance & throbbing & 2 & 0.07 & 0 & $0.00+$ & 17.4168870517850898432 .00 \\
\hline 34 & Concordance & thats & 2 & 0.07 & 0 & $0.00+$ & 17.4168870517850898432 .00 \\
\hline 35 & Concordance & rudely & 2 & 0.07 & 0 & $0.00+$ & 17.4168870517850898432 .00 \\
\hline 36 & Concordance & rico & 2 & 0.07 & 0 & $0.00+$ & 17.4168870517850898432 .00 \\
\hline 37 & Concordance & pluckest & 2 & 0.07 & 0 & $0.00+$ & 17.4168870517850898432 .00 \\
\hline 38 & Concordance & nymphs & 2 & 0.07 & 0 & $0.00+$ & 17.4168870517850898432 .00 \\
\hline 39 & Concordance & mon & 2 & 0.07 & 0 & $0.00+$ & 17.4168870517850898432 .00 \\
\hline 40 & Concordance & leialala & 2 & 0.07 & 0 & $0.00+$ & 17.4168870517850898432 .00 \\
\hline 41 & Concordance & leia & 2 & 0.07 & 0 & $0.00+$ & 17.4168870517850898432 .00 \\
\hline 42 & Concordance & hyacinth & 2 & 0.07 & 0 & $0.00+$ & 17.4168870517850898432 .00 \\
\hline 43 & Concordance & clutch & 2 & 0.07 & 0 & $0.00+$ & 17.4168870517850898432 .00 \\
\hline 44 & Concordance & barges & 2 & 0.07 & 0 & $0.00+$ & 17.4168870517850898432 .00 \\
\hline 45 & Concordance & Wallala & 2 & 0.07 & 0 & $0.00+$ & 17.4168870517850898432 .00 \\
\hline 46 & Concordance & Sweet_Thames & 2 & 0.07 & 0 & $0.00+$ & 17.4168870517850898432 .00 \\
\hline 47 & Concordance & Mrs._Porter & 2 & 0.07 & 0 & $0.00+$ & 17.4168870517850898432 .00 \\
\hline 48 & Concordance & London_bridge & 2 & 0.07 & 0 & $0.00+$ & 17.4168870517850898432 .00 \\
\hline 49 & Concordance & broken & 5 & 0.17 & 25 & $0.01+$ & $17.13 \quad 1432.65$ \\
\hline 50 & Concordance & only & 14 & 0.48 & 295 & $0.13+$ & $15.51 \quad 263.68$ \\
\hline 51 & Concordance & upon & 7 & 0.24 & 72 & $0.03+$ & 645.04 \\
\hline 52 & Concordance & red & 6 & 0.21 & 52 & $0.02+$ & 784.22 \\
\hline 53 & Concordance & twit & 3 & 0.10 & 6 & $0.00+$ & $14.81 \quad 3731.63$ \\
\hline 54 & Concordance & wrinkled & 2 & 0.07 & 1 & $0.00+$ & 13.6115226 .52 \\
\hline 55 & Concordance & stony & 2 & 0.07 & 1 & $0.00+$ & 13.6115226 .52 \\
\hline 56 & Concordance & stirring & 2 & 0.07 & 1 & $0.00+$ & 13.6115226 .52 \\
\hline 57 & Concordance & phoenician & 2 & 0.07 & 1 & $0.00+$ & 13.6115226 .52 \\
\hline 58 & Concordance & phlebas & 2 & 0.07 & 1 & $0.00+$ & 13.6115226 .52 \\
\hline 59 & Concordance & of_a_winter & 2 & 0.07 & 1 & $0.00+$ & $13.61 \quad 15226.52$ \\
\hline 60 & Concordance & hooded & 2 & 0.07 & 1 & $0.00+$ & 13.6115226 .52 \\
\hline 61 & Concordance & gaily & 2 & 0.07 & 1 & $0.00+$ & 13.6115226 .52 \\
\hline 62 & Concordance & divan & 2 & 0.07 & 1 & $0.00+$ & 13.6115226 .52 \\
\hline 63 & Concordance & Richmond & 2 & 0.07 & 1 & $0.00+$ & 13.6115226 .52 \\
\hline
\end{tabular}

\section{Screenshot (3) Keywords by Wmatrix}

Screenshot 3 shows keyness results retrieved by Wmatrix.

\subsection{Key Semantic Domains}

Semantic domains enable readers/researchers locate semantic categories of words. Wmatrix has this unique tool of gathering words under suitable domains. In this way, it facilitates examining thedominant group of words to understand thematic ideas. 


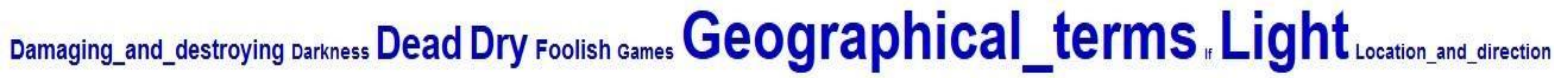
Menta_actions_and_processes Moving,_coming_and_going Negative Non-existing Not_examined Objects_generally Parts_of_buildings Plants Pronouns Quantities:_little Sailing,_swimming,_etc. Sensory:_Sound Senson:_Touch Sound:_auiet speres_commonature Stationary Substances_and_materials:_Liquid Substances_and_materials:_Solid Substances_and_materials:_Gas Temperature:_Hot_I_on_fire Uninterested/bored/unenergetic Unmatched voenersengen Weather

Screenshot (4) Key semantic domains in The Waste Land

Screenshot (4) shows the most significant key semantic domains in the poem. Words with larger fontshave more importance than words with small fonts. Key domains help to give readers an idea of the main points and ideas proposed by the poet.

The most prominent semantic domains in the poem are:

\section{Table (1) Key semantic domains in The Waste Land}

\begin{tabular}{|c|l|l|}
\hline No & Semantic domains & \multicolumn{1}{|c|}{$\begin{array}{c}\text { Words within these domains from } \text { The } \\
\text { Wasteland }\end{array}$} \\
\hline .1 & Anatomy and psychology & $\begin{array}{l}\text { Eyes, ears, finger, heart, feet, breasts, hands, } \\
\text { bones, faces, belly, hair... }\end{array}$ \\
\hline .2 & Colour and colour patterns & $\begin{array}{l}\text { Shadow, white, black, golden, glitter, red, } \\
\text { brown, violet }\end{array}$ \\
\hline .3 & Dead & $\begin{array}{l}\text { Burial, drowned, death, corpus, departed, } \\
\text { obituaries,dying }\end{array}$ \\
\hline .4 & Geographical terms & $\begin{array}{l}\text { Rivers, land, canal, sea, hill, desert, earth, } \\
\text { mountain, shore, sandy, plains }\end{array}$ \\
\hline .5 & Light & $\begin{array}{l}\text { Sunlight, shone, moonlight, rays, candle- } \\
\text { flames,light, tourchlight }\end{array}$ \\
\hline .6 & Substances, materials and liquids & $\begin{array}{l}\text { Water, drop, drip, oil, tar, damp } \\
\text { Rain, thunder, fog, wind, snow, clouds }\end{array}$ \\
\hline .7 & Weather & $\begin{array}{l}\text { He, she, they, you, I, his, her, their, my, we, } \\
\text { your, it, yourself, its }\end{array}$ \\
\hline .8 & Pronouns &
\end{tabular}




\begin{tabular}{|c|c|c|c|c|c|}
\hline \multicolumn{3}{|c|}{65 occurrences. } & \multicolumn{3}{|c|}{ Extend context } \\
\hline from the Hyacinth garden, Your & arms & full, and your hair wet, I coul & & More & I Full \\
\hline rden, Your arms full, and your & hair & wet, I could not Speak, and my & 2 & More & Full \\
\hline wet, I could not Speak, and my & eyes & failed, I was neither Living nor & 3 & More & Full \\
\hline knew nothing, Looking into the & heart & of light, the silence. Oed und & 4 & More & Full \\
\hline ( Those are pearls that were his & eyes & . Look !) Here is Belladonna, $t$ & & More । & Full \\
\hline here the Wheel, And here is the & one-eyed & merchant, and this card, Which & & More & Full \\
\hline , is something he carries on his & back & , Which I am forbidden to see. I & 7 & More & Full \\
\hline hs, short and infrequent, were & exhaled & , And each man fixed his eyes bef & 8 & More & Full \\
\hline exhaled, And each man fixed his & eyes & before his feet. Flowed up the $h$ & & More & Full \\
\hline ch man fixed his eyes before his & feet & - Flowed up the hill and down Kin & 10 & More & Full \\
\hline don peeped out ( Another hid his & eyes & behind his wing ) Doubled the fla & 11 & More I & Full \\
\hline world pursues, Jug Jug to dirty & ears & - And other withered stumps of ti & 12 & More | & Full \\
\hline irelight, under the brush, her & hair & Spread out in fiery points Glowed & 13 & More & Full \\
\hline hen would be savagely still . My & nerves & are bad tonight. Yes, bad. Sta & 14 & More & Full \\
\hline ey Where the dead men lost their & bones & . What is that noise ? The wind u & 15 & More & Full \\
\hline I Those are pearls that were his & eyes & - Are you alive, or not? Is the & 16 & More & Full \\
\hline am, and walk the street With my & hair & down, so. What shall we do tomo & 17 & More & Full \\
\hline game of chess, Pressing lidless & eyes & and waiting for a knock upon the & 18 & More & Full \\
\hline he gave you To get yourself some & teeth & . He did, I was there. You have & 19 & More & Full \\
\hline rivers tent is broken : the last & fingers & of leaf Clutch and sink into the & 20 & More & Full \\
\hline eak not loud or long. But at my & back & in a cold blast I hear The rattle & 21 & More & Full \\
\hline$d$ blast I hear The rattle of the & bones & , and chuckle spread from ear to & 22 & More & Full \\
\hline bones, and chuckle spread from & ear & to ear. A rat crept softly throu & 23 & More & Full \\
\hline , and chuckle spread from ear to & ear & - A rat crept softly through the & 24 & More & Full \\
\hline he vegetation Dragging its slimy & belly & on the bank While I was fishing $i$ & 25 & More & Full \\
\hline fathers death before him. White & bodies & naked on the low damp ground And & 26 & More & Full \\
\hline naked on the low damp ground And & bones & cast in a little low dry garret, & 27 & More & Full \\
\hline dry garret, Rattled by the rats & foot & only, year to year. But at my $b$ & 28 & More & Full \\
\hline only, year to year. But at my & & from time to time I hear The soun & & More & Full \\
\hline
\end{tabular}

Screenshot (5) Retrieval Results of the Words under the Domain of Anatomy and Psychology

\section{Conclusion}

Analyzing literary text manually (qualitatively) has a noticeable significance, but analyzing text by integrating both qualitative and quantitative approaches lead to much more significant and accurate results. The numbers and calculations retrieved by the tools of the computer enable researchers to focus on details that can be missed by manual analysis. It is, thus, crucial to merge both methodologies to reach an accurate and objective interpretation of any literary text. 


\section{REFERENCES}

Anthony, L. (2004). AntConc: A learner and classroom-friendly, multi-platform corpus analysis toolkit. proceedings of IWLeL, 7-13.

Baker, P., Haredie, A., \& McEnery, T.(2006).A glossary of corpus linguistics. Edinburgh, EdinburghUniversity Press.

Brooke, J., Hammond, A., \& Hirst, G. (2015). Distinguishing Voices in The Waste Land usingComputational Statistics. LiLT (Linguistic Issues in Language Technology), 12.

Bujanova, K. (2013). A corpus-stylistic analysis of Mitchell's gone with the wind and Hemingway's farewell to arms.(Master's thesis). Retrieved from http://www.duo.no/handle/10852/37048.pdf

Burke, M. (2014).The Routledge handbook of stylistics. Abingdon, Utrecht University.

Culpeper, J. (2009). Keyness: Words, parts-of-speech and semantic categories in the character-talk ofShakespeare's Romeo and Juliet. International Journal of Corpus Linguistics, 14(1), 29-59.

Ho, Y.(2011).Corpus stylistics in principle and practice: A stylistic exploration of John Fowles' TheMagus. A \& C Black.

Hunston, S. (2002) Corpora in applied linguistics, Cambridge: Cambridge University Press.

Jaafar, E.(2014). "A Stylistic Analysis of Two Selected Poems". Journal of the College of Education for Women, Vol. 25, no. 1, https://jcoeduw.uobaghdad.edu.iq/index.php/journal/article/view/722.

Jaafar, E. (2019). Examining Seamus Heaney's Poem ": A Corpus Stylistic Approach. Al Ustath Journal for Human and Social Sciences, 58(1), 17-26. Retrieved from https://alustath.uobaghdad.edu.iq/index.php/UJIRCO/article/view/826

Mahlberg, M., \& Smith, C. (2012). Dickens, the suspended quotation and the corpus. Language and Literature, 21(1), 51-65.

Mahlberg, M.(2014).Corpus stylistic.In M.Burke(Ed),The Roultedge handbook of stylistics(pp.378-380).Abingdon:Roultedge.

Mahlberg, M., \& McIntyre, D. (2011). A case for corpus stylistics: Ian Fleming's Casino Royale. English Text Construction, 4(2), 204-227.

McIntyre, D., \& Archer, D. (2010). A corpus-based approach to mind style. Journal of LiterarySemantics, 39(2), 167-182.

North, M. (2001). The Waste Land: A Norton Critical Edition. Ed. Michael North. NY: Norton.

McHale B. \& Stevenson R. (Eds.) (2006). Edinburgh Companion to Twentieth Century Literatures in English. Edinburgh: Edinburgh University Press. 
Rayson, P. (2003). Matrix: A statistical method and software tool for linguistic analysis throughcorpus comparison (Doctoral dissertation, Lancaster University).

Rayson, P. (2008). From keywords to key semantic domains, International Journal of CorpusLinguistics, 13 (4): 519-549.

Rayson, P. (2009). Wmatrix: A web-Based Corpus Processing Environment. School of computing and communications, Lancaster University http://ucrel.lancs.ac.uk/wmatrix/

Wynne, M. (2005).Stylistics: Corpus approaches. (Master's thesis). Retrieved from http://www.pala.an.uk/uploads/2/5/1/0/25105678.pdf

\section{AUTHOR'S BIO}

Eman Adil Jaafar is an assistant professor of linguistics at the Department of English/ College of Education for Women / University of Baghdad. Her research interests include but not restricted to stylistics, corpus and cognitive stylistics and applied linguistics. 